\title{
Lusioersily
}

\section{Determination of total reduced thiol levels in plasma using a bromide substituted quinone}

Lobo, GAM., Chitre, SA., Rathod, SM., Smith, RB., Leslie, R., Livingstone, C., \& Davis, J. (2007). Determination of total reduced thiol levels in plasma using a bromide substituted quinone. Electroanalysis, 19(24), 2523-2528. https://doi.org/10.1002/elan.200703977

Link to publication record in Ulster University Research Portal

Published in:
Electroanalysis

Publication Status:

Published (in print/issue): 01/12/2007

DOI:

10.1002/elan.200703977

\section{Document Version}

Publisher's PDF, also known as Version of record

\section{General rights}

Copyright for the publications made accessible via Ulster University's Research Portal is retained by the author(s) and / or other copyright owners and it is a condition of accessing these publications that users recognise and abide by the legal requirements associated with these rights.

\section{Take down policy}

The Research Portal is Ulster University's institutional repository that provides access to Ulster's research outputs. Every effort has been made to ensure that content in the Research Portal does not infringe any person's rights, or applicable UK laws. If you discover content in the Research Portal that you believe breaches copyright or violates any law, please contact pure-support@ulster.ac.uk. 
Full Paper

\title{
Determination of Total Reduced Thiol Levels in Plasma Using a Bromide Substituted Quinone
}

\author{
Grace-Ann M. Lobo, ${ }^{\mathrm{a}}$ Sneha A. Chitre, ${ }^{\mathrm{a}}$ Spandan M. Rathod, ${ }^{\mathrm{a}}$ Robert B. Smith, ${ }^{\mathrm{a}}$ Ray Leslie, ${ }^{\mathrm{a}}$ Callum Livingstone, \\ James Davis ${ }^{\mathrm{a}}$ \\ a School of Biomedical and Natural Sciences, Nottingham Trent University, Nottingham, NG11 8NS, UK \\ *e-mail: James.davis@ntu.ac.uk \\ b Royal Surrey County Hospital NHS Trust, Guildford, GU2 7XH, UK
}

Received: July 02, 2007

Accepted: July 23, 2007

\begin{abstract}
The exploitation of 2-bromo-1,4-naphthoquinone (NQBr) as a selective redox label for the determination of reduced thiol functionalities (RSH) has been investigated. The system is selective for RSH functionality, giving distinct voltammetric signals for glutathione and cysteine but can also be adapted for broad spectrum thiol detection. Ion chromatographic protocols based on conductimetric detection enable total RSH analysis (protein and monomolecular moieties) within human plasma. Bromide released through the reaction can be easily quantified and integrated within normal IC measurements. The efficacy of the approach has been assessed and the response validated through comparison with the standard colorimetric technique.
\end{abstract}

Keywords: Plasma, Thiol, Bromide, Ion chromatography, Oxidative stress

DOI: 10.1002/elan.200703977

\section{Introduction}

The clinical value of measuring reduced thiol concentration has long been recognized and it has been suggested as a semiquantitative handle that, in the appropriate context, could be used to monitor the progress of illnesses exacerbated by oxidative stress processes $[1,2]$. The depletion in concentration of the various sulfur moieties has also been proffered as a possible early warning indicator for the onset of various clinical complications that include: diabetes [3$5]$; various forms of cancer $[6,7]$; kidney function $[8,9]$ and preeclampsia $[10,11]$. Utilization of such measurements within routine clinical settings, however, has largely been restricted as a consequence of the expense and difficulties associated with the analysis. While more commonly associated with research studies, there is considerable merit in making such measurements available within mainstream health care provision. The aim of the present communication has been to assess the electroanalytical options that a naphthoquinone-bromide detection system can provide for the analysis of thiols within conventional biofluids such as plasma.

Several quinone systems have been investigated as potential indicators for reduced thiol species [12-14]. The advantage of the system proposed herein relies on the versatility of the fact that there are a number of detection routes through which the analytical signal can be extracted. The core detection pathway is detailed in Scheme 1 and involves the nucleophilic substitution of a bromide derivatized quinone indicator (I). In the presence of reduced thiols

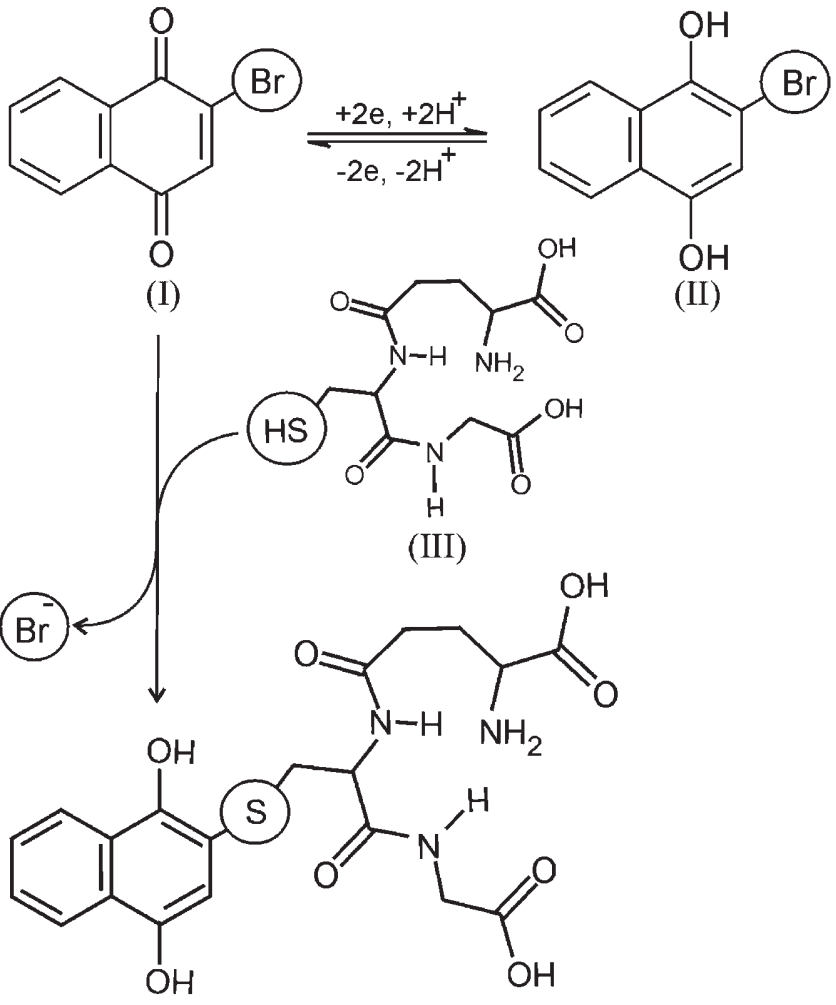

(IV) 
such as glutathione (III), it could be anticipated that a relatively rapid reaction would occur leading to the formation of the corresponding quinone-thiol conjugate (IV) and release of bromide ion. The analytical options stem from examining either the consumption of the naphthoquinone-bromide indicator, the production of the conjugate or the release of bromide ion. The last two are arguably better solutions as, in either case, a positive increment to the analytical signals should be obtained.

The investigation has sought to assess the electrochemical properties possessed by the quinone system in relation to its use as a label for reduced thiol species. Selectivity, sensitivity, the extraction of an unambiguous signal and the development of a system that can be readily transferred to the analysis of real samples (human plasma) are the core issues that need to be addressed.

\section{Experimental}

\subsection{Methods and Materials}

All reagents were of the highest grade available and used without further purification. All standards were prepared using UHQ deionized water (Elga,UK) with a resistivity of not less than $18 \mathrm{M}^{-1} \mathrm{~cm}$. Electrochemical measurements were conducted using a $\mu$ Autolab type III computer controlled potentiostat (Eco-Chemie, Utrecht, The Netherlands) using a three electrode configuration consisting of a glassy carbon working electrode $(3 \mathrm{~mm}$ diameter, BAS Technicol, UK), a platinum wire counter electrode and a $3 \mathrm{M} \mathrm{NaCl} \mathrm{Ag} \mathrm{|} \mathrm{AgCl}$ half cell reference electrode (BAS Technicol, UK). All measurements were done under nitrogen. Chromatographic analysis was carried out in isocratic mode with a Dionex 120 DX series ion chromatography system with a $25 \mu \mathrm{L}$ sample loop. The mobile phase consisted of nitrogen purged sodium carbonate/bicarbonate $(3.5 \mathrm{mM} / 1 \mathrm{mM})$ at a flow rate of $1.5 \mathrm{~mL} / \mathrm{min}$. Detection was achieved through the use of an integrated conductivity cell thermostatted at $35^{\circ} \mathrm{C}$. Absorbance spectra were obtained using a Perkin Elmer Lambda 25 spectrometer. NMR spectra were measured on a JEOL ECX $400 \mathrm{MHz}$ spectrometer. Chemical shifts are reported in parts per million (ppm) downfield from tetramethylsilane (TMS). Mass spectra were recorded on a Micromass Platform LC-ESIMS. Flash chromatography was performed on 40-63 silica gel (Merck). IR data was recorded on a Perkin Elmer Spectrum 100 Series with a Universal ATR Sampling Accessory.

\subsection{Preparation of 2-Bromo-1,4-Naphthoquinone (NQBr)}

The preparation route followed was adapted from a previous method [15] with the reagents obtained as the highest grade available from Sigma-Aldrich. These were used as received without further purification. A solution of 1-naphthol ( $0.72 \mathrm{~g}, 0.50 \mathrm{mmol})$ in glacial acetic acid $(50 \mathrm{~mL})$ was added to a stirring solution of $\mathrm{N}$-bromosuccinimide $(3.56 \mathrm{~g}, 20 \mathrm{mmol})$ in $2: 1$ water/glacial acetic acid $(150 \mathrm{~mL})$ at room temperature over a period of 60 minutes. The mixture was stirred at room temperature for $12 \mathrm{~h}$ followed by heating to $50-60^{\circ} \mathrm{C}$ with stirring for $1 \mathrm{~h}$. Subsequently, water $(100 \mathrm{~mL})$ was added to the reaction mixture followed by extraction into ethyl acetate $(3 \times 100 \mathrm{~mL})$. The organic layer was combined and washed with $5 \mathrm{M} \mathrm{NaHCO}_{3}$ solution, dried over $\mathrm{Na}_{2} \mathrm{SO}_{4}$, filtered and concentrated under vacuum to yield the crude product. Purification using column chromatography on silica gel with ethyl acetate and hexane (7:3) as eluent yielded the 2-bromo-1,4-naphthoquinone $(0.65 \mathrm{~g}, 54.4 \%)$ as a yellow powder.

${ }^{1} \mathrm{H} \mathrm{NMR}\left(\mathrm{CDCl}_{3}\right)$ : $\delta 8.19-8.17(\mathrm{~m}, 1 \mathrm{H}, \mathrm{Ar}-\mathrm{H}), 8.10-8.08$ $(\mathrm{m}, 1 \mathrm{H}, \mathrm{Ar}-\mathrm{H}), 7.80-7.77(\mathrm{~m}, 2 \mathrm{H}, \mathrm{Ar}-\mathrm{H}), 7.52(\mathrm{~s}, 1 \mathrm{H}$, $\mathrm{Ar}-\mathrm{H}) ;{ }^{13} \mathrm{C}$ NMR $\left(\mathrm{CDCl}_{3}\right): \delta 126.9,127.9,131.7,134.2$, 134.5, 134.6, 140.2, 140.4, 177.9, 182.5; IR (ATR): 3055 $(\mathrm{Ar}-\mathrm{H}), 1676(\mathrm{C}=\mathrm{O}), 1656(\mathrm{C}=\mathrm{O}), 1588(\mathrm{C}=\mathrm{O}), 1292$ $(\mathrm{C}=\mathrm{O}), 1244(\mathrm{C}=\mathrm{O}), 1058$ (Ar-Br); ESI-MS $(\mathrm{m} / \mathrm{z}) 236$ $[\mathrm{M}+\mathrm{H}]^{-}$.

\subsection{Clinical Samples}

A clinical trial involving five volunteers was conducted. The participants were aged between 24 and 37. Blood was collected in heparinized gel permeation vaccutainers and then centrifuged at $3000 \mathrm{rpm}$ for 5 minutes. The plasma was withdrawn and stored at $-18^{\circ} \mathrm{C}$. The concentration of total reduced thiol was assessed prior to storage and after defrosting using an established Ellman's Assay protocol. This consisted of adding $0.1 \mathrm{~mL}$ of either standard solution or plasma sample to $1.9 \mathrm{~mL}$ of Ellman's Reagent $(\mathrm{pH} 8)$ with the calibration and analysis data taken at $412 \mathrm{~nm}[3,5,6$, $14,16]$.

\subsection{Ion Chromatographic Assay Procedures}

A standard solution (5 mM) of 2-bromo-1,4-naphthoquinone $(\mathrm{NQBr})$ was prepared in HPLC grade acetonitrile. Calibration solutions were prepared by dilution from a stock solution of glutathione $(10 \mathrm{mM}$ dissolved in electrolyte containing chloride, nitrate and phosphate, each at $100 \mathrm{mg} /$ $\mathrm{L}$ ). The analysis samples were prepared by adding $325 \mu \mathrm{L}$ of the NQBr solution to $175 \mu \mathrm{L}$ of the appropriate standard $(0.025-1.0 \mathrm{mM})$. The solution was gently mixed and then injected into the IC through a 0.45 micron filter (Millipore). An analogous procedure was used for the plasma samples. Upon the introduction of the acetonitrile indicator solution, rapid precipitation of protein was observed. The resulting slurry was then centrifuged at $10000 \mathrm{rpm}$ for 5 minutes and the supernatant injected as before. 


\section{Results and Discussion}

Cyclic voltammograms detailing the response of $\mathrm{NQBr}$ $(0.5 \mathrm{mM}, \mathrm{pH} 7)$ towards increasing additions of glutathione at a glassy carbon electrode are detailed in Figure $1 \mathrm{~A}$. In the absence of the thiol, the quinone exhibits the characteristic $2 \mathrm{e}, 2 \mathrm{H}^{+}$reduction $(-0.18 \mathrm{~V})$ and corresponding oxidation $(-0.11 \mathrm{~V})$. Upon introducing glutathione $(55 \mu \mathrm{M}$ increments), the reduction process diminishes in magnitude and a second reduction process begins to emerge at $-0.26 \mathrm{~V}$. The latter corresponds to the production of the quinone-thiol conjugate (NQ-SG) as indicated in Scheme 1 (IV). The conjugate process can be seen more clearly when examining the square-wave voltammograms (Fig. 1B).

Similar responses were observed from $\mathrm{pH} 3$ to $\mathrm{pH} 9$, sufficient to cover most biofluid environments, with the
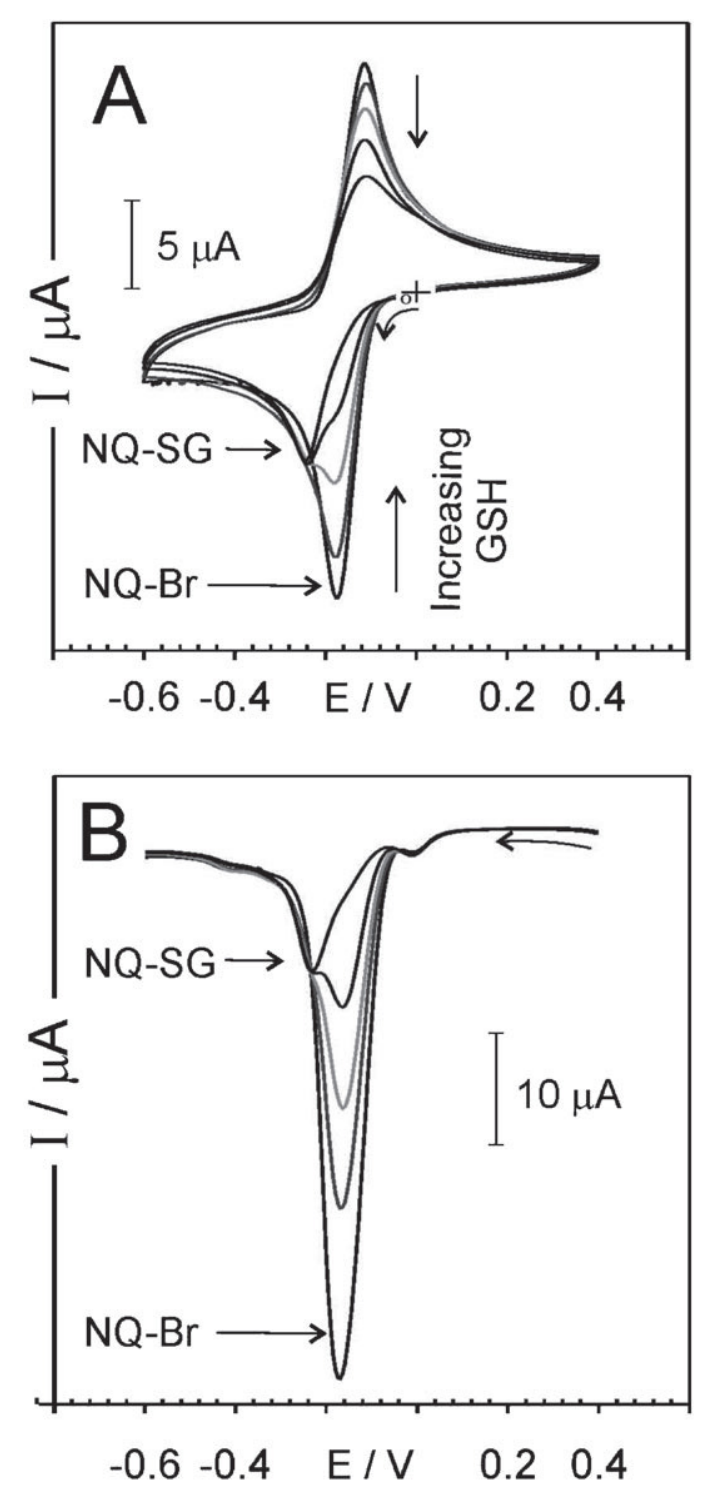

Fig. 1. Cyclic (A) and square-wave (B) voltammograms detailing the response of a glassy carbon electrode towards $0.5 \mathrm{mM} \mathrm{NQBr}$ $(\mathrm{pH} 7)$ in the presence of increasing glutathione, GSH, $(55 \mu \mathrm{M})$. Scan Rate: $0.1 \mathrm{~V} / \mathrm{s}$. response to glutathione $(55 \mu \mathrm{M})$ found to be consistent as shown in Figure 2. Degradation of the NQBr indicator at pH 9 can be seen with the appearance of a number of secondary peaks observable on the voltammogram in the absence of any thiol. These increase with time and highlight the reactivity of the bromide derivative but also its instability at the higher $\mathrm{pH}$. An important point to note however is the continued reactivity toward the thiol at low $\mathrm{pH}$. This is in marked contrast to conventional quinone systems. The chief advantage, beyond simply increasing the range of applicability, is that it should enhance selectivity towards thiol functionality as it could be expected that most, if not all amine functionality will be protonated at such low $\mathrm{pH}$ and hence possess negligible nucleophilic character.

The response of the NQBr indicator to cysteine $(\mathrm{CSH})$ is highlighted in Figures $3 \mathrm{~A}$ and $3 \mathrm{~B}$. The voltammetric profiles are, on initial inspection, similar to that observed with glutathione in that the reduction peak for the NQBr indicator decreases with increasing additions of cysteine $(55 \mu \mathrm{M})$. Closer examination of the cyclic voltammograms, detailed in Figure 3A, reveals the appearance of a new species with the reduction/oxidation peaks observed at $-0.46 \mathrm{~V}$ and $-0.37 \mathrm{~V}$ respectively. Inspection of the squarewave response under the same conditions (Fig. 3B) however highlights the existence of two reaction products. This is in contrast to the response with glutathione where only a single reaction product was observed. The former is ascribed to the formation of the simple conjugate, as per glutathione [17], however, the second, more cathodic process is attributed to the subsequent cyclization of the initial conjugate. The proposed reaction pathway is outlined in Scheme 2. The absence of the second reaction product in Figure 1 is most likely due to the inability of the glutathione to form the six member ring possessed by the quinone-cysteine product. Support for the cyclization process has been found in studies

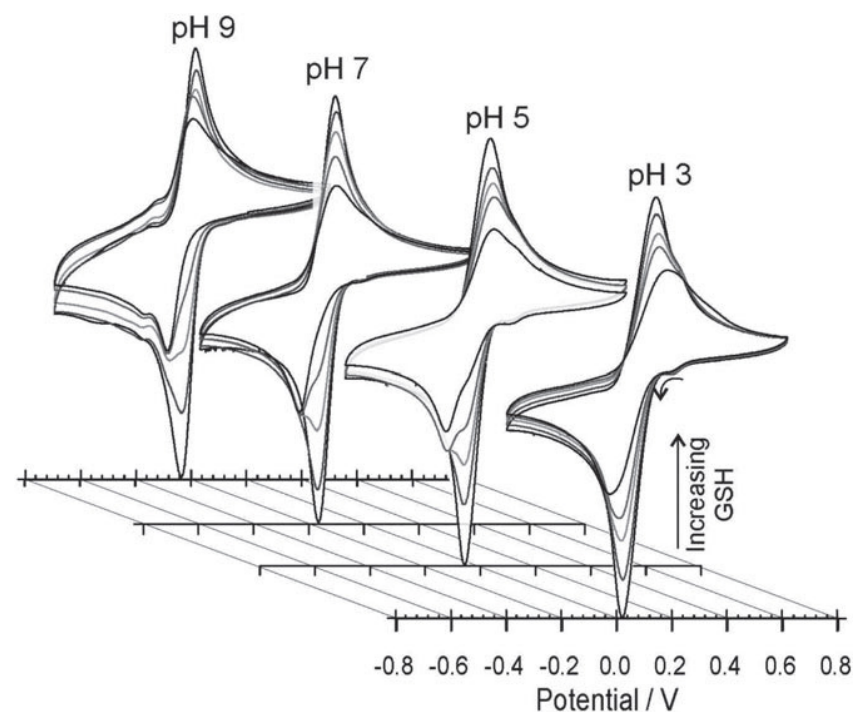

Fig. 2. Cyclic voltammograms highlighting the influence of $\mathrm{pH}$ on the response of a glassy carbon electrode towards $0.5 \mathrm{mM}$ $\mathrm{NQBr}$ in the presence of increasing cysteine $(55 \mu \mathrm{M})$. Scan Rate: $0.1 \mathrm{~V} / \mathrm{s}$. 

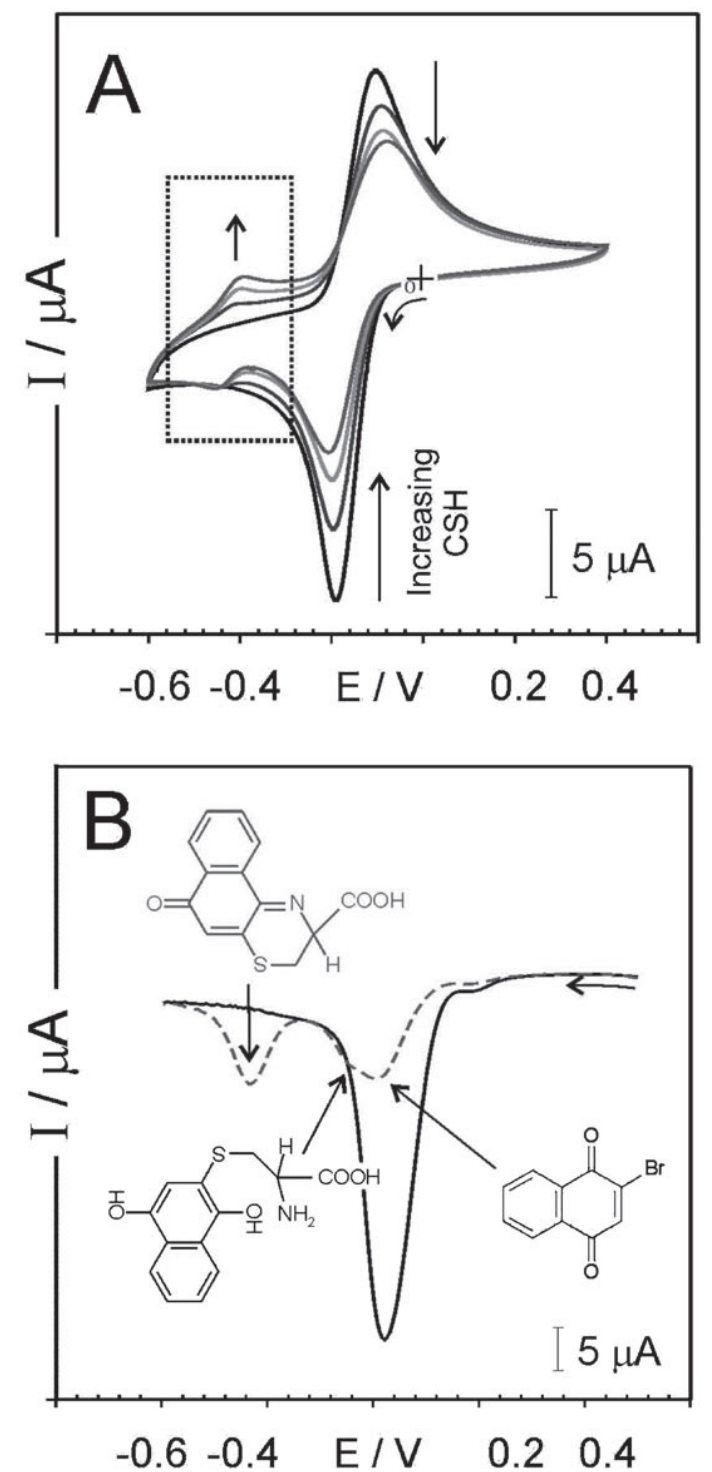

Fig. 3. Cyclic (A) and square-wave (B) voltammograms detailing the response of a glassy carbon electrode towards $0.5 \mathrm{mM} \mathrm{NQBr}$ $(\mathrm{pH} 7)$ in the presence of increasing cysteine, $\mathrm{CSH},(55 \mu \mathrm{M}$, dashed line). Scan Rate: $0.1 \mathrm{~V} / \mathrm{s}$.

of thiol interactions with hypocrellin derivatives and confirmed by both NMR and mass spectroscopic analysis [18]. In the latter, cysteine has been found to react with quinone moieties of the macromolecular species in much the same way as the $\mathrm{NQBr}$ with the consequent cyclic imine (Scheme 2, VII-VIII).

The electroanalytical exploitation would, at first sight, appear to be quite promising and is strengthened by the fact that the quinone indicator is insensitive to most other functionalities under the short timescale of the voltammetric investigation $(5 \mathrm{~min})$. There were no responses to alkyl or aryl amines nor imidazole derivatives, such as histidine, even when present at a 100 fold excess [13]. The main problem however relates to the fact that the analytical signal is derived from the decrease in the quinone reduction peak. While the indicator is selective for RSH functionalities, the<smiles>NC(CSc1cc(O)c2ccccc2c1O)C(=O)O</smiles>

(V)<smiles>[AlH2]</smiles><smiles>CC1CC1O</smiles><smiles>O=C(O)C1CSc2cc(O)c3ccccc3c2N1</smiles>

(VIII)

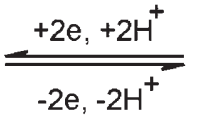<smiles>CC1CSC2=CC(=O)c3ccccc3C2=N1</smiles>

(VII)
Scheme 2. Cyclization of the cysteine-quinone conjugate.

concentration of the thiol derived from using the inverse of the peak height would make such a strategy highly susceptible to errors resulting from simple changes in electrode area. This would be particularly true where biological fluids are being analyzed as surface fouling, inevitable in such environments, would lead to an overestimate of the thiol concentration.

The emergence of the conjugate peaks in the square-wave voltammograms (Figure 1B and 3B), in contrast to the previous approach, provide positive signals. Unfortunately, they are not sufficiently resolved to allow unambiguous quantification. The secondary product observed with cysteine (Fig. 3B), however, does provide an option for the selective quantification of this component. The response was found to be non linear but rapidly plateaus. There is an adsorptive component to signal as expected given the tricyclic nature of the product (Scheme 2, VII - VIII). While it could be adapted to the measurement of low levels of cysteine, the irreproducible nature of the system would impede widespread adoption of such an approach.

The main value of the $\mathrm{NQBr}$ indicator is more likely to lie in its integration within hybrid liquid chromatography (LC) systems in which column resolution of the various components will allow unambiguous quantification of the thiol content. It could be anticipated that the quinone redox centre would provide a versatile handle for electrochemical detection within conventional LC systems. There is however an alternative strategy, ion chromatography of the resulting 
bromide ion. As the $\mathrm{NQBr}$ is selective for reduced thiol functionality, then the release of bromide would represent the stoichiometric equivalent of the available SH functionalities. This should provide a simple means of acquiring the total RSH content.

The ion chromatographic response of the $\mathrm{NQBr}$ indicator towards increasing glutathione $(0.06 \mathrm{mM}-1.5 \mathrm{mM})$ is shown in Figure 4A. Four peaks are observed throughout and correspond to chloride, nitrite, nitrate and phosphate, all of which are liable to be found within most typical biofluids. The release of bromide as a consequence of the $\mathrm{NQBr}$-glutathione reaction is observed as a distinct peak between the nitrite and nitrate signals. Near identical responses are observed for cysteine and albumin, as expected given that bromide is the principal agent in all cases, and allows the measurement of both low molecular weight and macromolecular species. The main requirement is the presence of the free $\mathrm{SH}$ group. There is, however, no opportunity for speciation, in contrast to LC methodologies, but the aim here has been focused on obtaining the total reduced thiol measurement. The response was linear over the range $15 \mu \mathrm{M}-3.5 \mathrm{mM}$ RSH. The calibration data relating to the bromide peak was found to be: Response $\left.(\mu \mathrm{S})=3.80 \times 10^{4}[\mathrm{~mol} / \mathrm{L} \mathrm{RSH}]-0.014, N=8, R^{2}=0.9997\right)$. The recoveries for 80 and $500 \mu \mathrm{M}$ glutathione were $92 \%$ and $96 \%$ respectively. The limit of detection was found to be $9 \mu \mathrm{M}$ (based on $3 s b$ ) and is more than adequate to cover the broad range $(300-600 \mu \mathrm{M})$ typical for total reduced thiol measurements within plasma [3-8].

\subsection{Clinical Study}

The ion chromatographic response to plasma before (dotted line) and after (solid line) treatment with the $\mathrm{NQBr}$ solution is shown in Figure 4B. The response towards the simple electrolyte solution is also included (inverted-dotted line) to enable the clear identification of the peaks. The central peak, while predominantly chloride, is liable to contain a host of components and it was not possible to isolate these in the present study. Clear resolution between the composite chloride peak, bromide and the other anionic electrolytes is possible and contrast the direct electrochemical measurements highlighted in Figures 1-3. Bromide is observable in the untreated plasma with the endogenous concentration between different plasma samples found to range from 49 $72 \mu \mathrm{M}$ and is consistent with the values found in previous investigations [19-21]. The presence of bromide in the untreated plasma does not unduly compromise the measurement as the appropriate correction can be made using a before and after subtraction. The results from the five plasma samples (after subtraction of endogenous bromide) are detailed in Table 1 along with the results obtained using the standard Ellman's reagent system $[3,5,6,16]$. In each case, the analysis was done in triplicate with the intra assay variation being less than $5 \%$. It can be argued that where gross changes in thiol concentration are to be used as a screening system for identifying underlying illness, then the
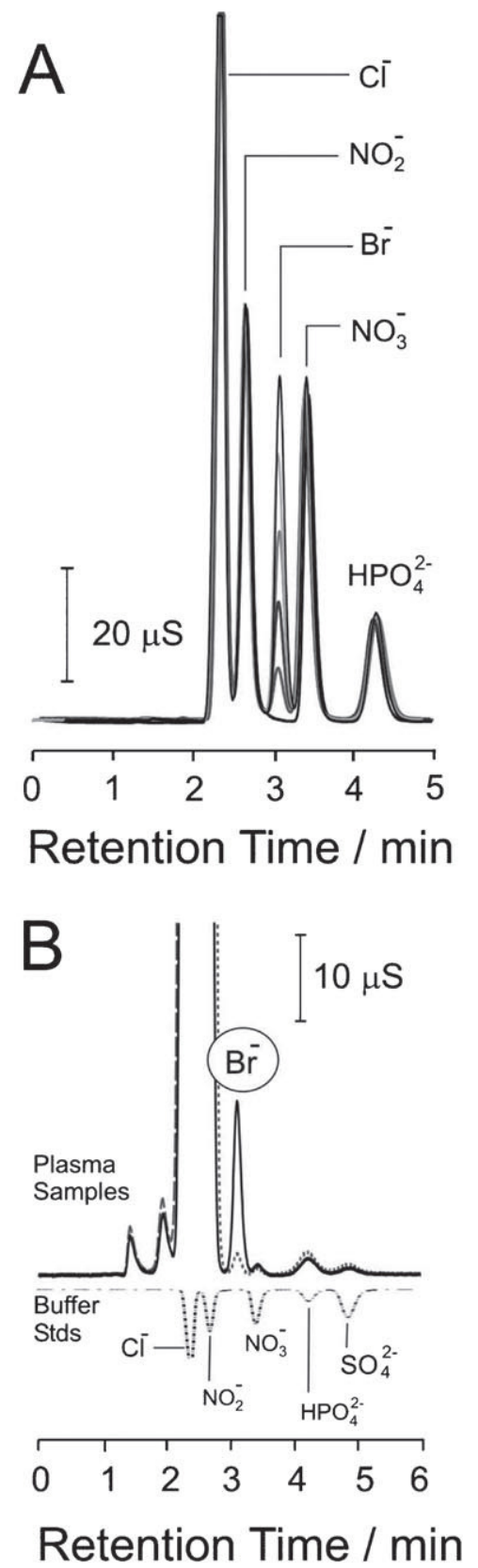

Fig. 4. Ion chromatograms detailing A) the release of bromide as a consequence of the reaction of NQBr with increasing concentrations of glutathione $(250 \mu \mathrm{M}$ increments) and $\mathrm{B})$ the response obtained to plasma before (dashed line) and after (solid line) reaction with $\mathrm{NQBr}$.

Table 1. Table 1. Plasma thiol concentrations. Each measurement based on three replicates.

\begin{tabular}{|c|c|c|c|c|c|}
\hline \multicolumn{2}{|c|}{ Plasma thiol } & \multicolumn{2}{|c|}{ NQBr IC } & \multicolumn{2}{|c|}{ Ellman's reagent } \\
\hline Gender & Age & $\mathrm{mM}$ & $(\% \mathrm{RSD})$ & $(\%$ RSD $)$ & $\mathrm{mM}$ \\
\hline M & 37 & 0.362 & $(3.8)$ & 0.373 & $(3.5)$ \\
\hline $\mathrm{F}$ & 24 & 0.365 & (2.6) & 0.361 & $(1.2)$ \\
\hline M & 30 & 0.334 & (3.2) & 0.374 & $(2.5)$ \\
\hline $\mathrm{F}$ & 27 & 0.406 & (3.2) & 0.401 & (2.9) \\
\hline $\mathrm{F}$ & 37 & 0.384 & (2.1) & 0.391 & (2.6) \\
\hline
\end{tabular}


relatively constant nature of the endogenous bromide will have little influence and hence only a single measurement would be necessary. This is corroborated by recent studies where the RSH levels measured in diabetics suffering from vascular complications were $25-33 \%$ lower than that of the corresponding control group [3,4]. While similar variations have been observed with preeclamptic pregnancies $[10,11]$, the difference can be substantially greater in cancer patients where, in the case of oral squamous cell carcinoma, the levels were decreased by more than $50 \%$ when compared with healthy controls [6]. This can represent a depletion of more than $0.25 \mathrm{mM}$ from the respective control group.

\section{Conclusions}

The bromo-quinone derivative provides a versatile platform from which to explore quinone-thiol interactions but the analytical exploitation is limited by poor resolution between the indicator and reaction product. Using the bromide ion released in the course of the reaction, however, provides a more valuable diagnostic handle. The potential of the latter is twofold, an early warning indicator for the onset of underlying oxidative injury and a marker that could allow the progress of the illness and the subsequent treatment to be assessed. Routine screening of RSH concentration could be easily achieved by minor modification to existing IC protocols. It overcomes the problems of dealing with highly colored matrices that afflict spectroscopic protocols such as Ellman's and, as demonstrated in Figure 2, can be used within matrices covering a wider $\mathrm{pH}$ range than that dictated by the spectroscopic system. More importantly, obviates the need for requesting a separate test set as it can be accomplished in the normal course of electrolyte measurements without compromising the integrity of the latter. Given that the system proposed here offers a relevant detection range, simplicity of operation and utilises established technology it should therefore be capable of widespread application.

\section{Acknowledgements}

The authors thank the EPSRC for financial support and the South West Surrey Local Region Ethics Committee (LREC) for approving the clinical investigation.

\section{References}

[1] I. C. West, Diabetic Med. 2000, 17, 17

[2] D. M. Townsend, K. D. Tew, H. Tapiero, Biomed. Pharmacother. 2003, 57, 145

[3] K. Komosinska-Vassev, K. Olczyk, P. Olczyk, K. WinszSzczotka, Diabetes Res. Clin. Pract. 2005, 68, 207

[4] E. Dursun, M. Timur, B. Dursun, G. Suleymanlar, T. Ozben, J Diabetes Complic. 2005, 19, 142

[5] T. A. Elhadd, F. Khan, G. Kirk, M. McLaren, R. W. Newton, S. A. Greene, J. J. E. Belch, Diabetes Care 1998, 21, 1990

[6] P. Subash, M. Das, A. Rao, Clin. Chim. Acta 2006, 368, 199

[7] I. A., Yilmaz, T. Akcay, U. Cakatay, A. Telci, S. Ataus, V. Yalcin, Internat. Urol. Nephrol. 2003, 35, 345

[8] B. P. Oberg, E. McMenamin, F. L. Lucas, E. McMonagle, J. Morrow, T. A. Ikizler, J. Himmelfarb, Kidney Internat. 2004, 65, 1009

[9] J. Mimic-Oka, T. Simic, L. Djukanovic, Z. Reljic, Z. Davicevic, Clin. Nephrol. 1999, 51, 233

[10] M. T. M. Raijmakers, P. L. M. Zusterzeel, E. A. P. Steegers, M. P. C. Hectors, P. N. M. Demacker, W. H. M. Peters, Obstetrics Gynecol. 2000, 95, 180

[11] E. M. Roes, J. C. M. Hendricks, M. T. M. Raijmakers, R. P. M. Steegers-Theunissen, P. Groenen, W. H. M. Peters, E. A. P. Steegers, Acta Obstetricia Gynecol. Scand. 2006, 85, 148

[12] O. Nekrassova, N. S. Lawrence, R. G. Compton, Talanta 2003, 60, 1085

[13] R. B. Smith, C. Canton, N. S. Lawrence, C. Livingstone, J. Davis, New J. Chem. 2006, 30, 1718

[14] S. Gracheva, C. Livingstone, J. Davis, Anal. Chemi. 2004, 76, 3833

[15] T. V. Nguyen, N. De Kimpe, Tetrahedron 2003, 59, 5941

[16] G. Ellman, Archives of Biochem. and Biophys. 1959, 82, 70

[17] K. G. Madsen, J. Olsen, C. Skonberg, S. H. Hansen, U. Jurva, Chem. Res Toxicol. 2007, 20, 821

[18] Y. Y. He, J. Y. An, W. Zou, L. J. Jiang, J. Photochem. Photobiol. B 1998, 44, 45

[19] J. P. Pascali, M. Trettene, F. Bortolotti, G. de Paoli, R. Gottardo, F. Tagliaro, J. Chromatogr. B 2006, 839, 2

[20] H. Tanaka, M. Nakajima, M. Fujisawa, M. Kasamaki, Y. Hori, H. Yoshikawa, S. Kitagawa, Biol. Pharmaceut. Bull. 2003, 26, 457

[21] O. Quinones, S. A. Snyder, J. A. Cotruvo, J. W. Fisher, Toxicology 2006, 221, 229. 